\title{
Acute liver injury in the course of COVID-19
}

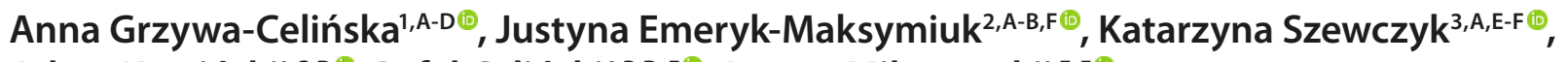

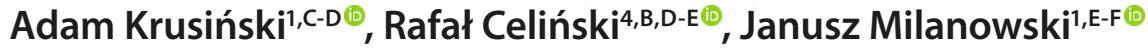 \\ ${ }^{1}$ Chair and Department of Pneumonology, Oncology and Allergology, Medical University, Lublin, Poland \\ ${ }^{2}$ Department of Internal Medicine in Nursing, Medical University, Lublin, Poland \\ ${ }^{3}$ Department of Pharmaceutical Botany, Medical University, Lublin, Poland \\ ${ }^{4}$ Department of Cardiology, Independent Public Provincial Specialist Hospital, Chełm, Poland \\ A - Research concept and design, B - Collection and/or assembly of data, C - Data analysis and interpretation, \\ $D$ - Writing the article, E - Critical revision of the article, F - Final approval of the article
}

Grzywa-Celińska A, Emeryk-Maksymiuk J, Szewczyk K, Krusiński A, Celiński R, Milanowski J. Acute liver injury in the course of CovID-19. Ann Agric Environ Med. 2021; 28(4): 729-732. doi: 10.26444/aaem/142232

\begin{abstract}
Although coronavirus disease 19 (COVID-19) most often affects the respiratory system, in the course of this disease, dysfunction of many other organs may also develop. The case is presented of a female patient, treated for a long time due to chronic obstructive pulmonary disease, complicated by chronic complete respiratory failure, and who was undergoing non-invasive mechanical ventilation at home. She was admitted to the Pneumonology Department due to exacerbation of the symptoms of her underlying disease. Several tests for SARS-CoV2 infection gave a negative result. During the patient's stay in the clinic, a rapid increase was observed in symptoms of respiratory failure, heart failure, and laboratory signs of acute liver damage. The next PCR test result proved to be positive. In addition to the case report, the possible impact of SARS-CoV2 infection on liver damage is also also discussed, along with a literature review on this topic.
\end{abstract}

- Key words

liver, COPD, transaminases, COVID-19

\section{INTRODUCTION}

COVID-19 is an infectious disease most often affecting the respiratory system, but can also affect many other systems and organs. One of the manifestations of this disease is acute liver damage, which may have a multifactorial aetiology in the course of this disease [1]. Firstly, the infection may overlap pre-existing liver disease. Moreover, drug-induced damage, as well as congestion caused by right ventricular heart failure or complications of COVID-19, such as pulmonary embolism, may also be of importance. The liver damage complicating the COVID-19 infection can increase the severity of the disease, leading to prolonged hospitalization and worsens the prognosis of survival $[1,2,3,4]$.

The case report presents a patient with acute liver injury in the course of COVID-19, with the exacerbation of chronic obstructive pulmonary disease, and includes a review of the latest literature on this topic.

\section{CASE REPORT}

The case is presented of a 75-year-old female patient with a history of chronic obstructive pulmonary disease (COPD) and chronic complete respiratory failure, undergoing a home oxygen treatment programme with non-invasive ventilation (NIV) in a bi-level positive airway pressure mode (bi-PAP). She was admitted to the Department of Pneumonology because of dyspnoe, increasing for 3 weeks (at 3 points on the modified Medical Research Council -

Adress for correspondence: Anna Grzywa-Celińska, Chair and Department of Pneumonology, Oncology and Allergology, Medical University, Jaczewskiego 8, 20-954 Lublin, Poland

E-mail: acelin@op.pl

Received: 12.07.2021; accepted: 13.09.2021; first published: 21.09 .2021
mMRC - scale), cough with expectoration of a small amount of yellowish discharge, and pain in the left shoulder. She was treated for arterial hypertension and chronic heart failure. A year earlier, she had been diagnosed with a peripheral pulmonary embolism (PE) and was taking rivaroxaban for anticoagulant treatment for 6 months. On admission, her blood saturation was $73 \%$ and raised to $87 \%$ with passive oxygen therapy. Respiratory rate - $15 / \mathrm{min}$, temperature $37^{\circ} \mathrm{C}$, blood pressure $-130 / 75 \mathrm{mmHg}$, and heart rate $-110 /$ min. On auscultation, no additional auscultation phenomena were audible. The electrocardiogram showed regular sinus tachycardia of 150 beats per minute with no evident signs of acute myocardial ischemia. Laboratory test results: C-reactive protein (CRP) - $7 \mathrm{mg} / \mathrm{l}$, ALT - $50 \mathrm{U} / \mathrm{l}$, troponin I $106 \mathrm{ng} / \mathrm{l}$, with a slight upward trend in subsequent determinations, $\mathrm{D}$-dimers $-3,500 \mu \mathrm{g} / \mathrm{l}$. All other results were normal. The measurement of arterial blood gases showed compensated respiratory acidosis. According to the radiologist, the changes found in the radiograph could partially meet the COVID-19 criteria, but the antigen test and two PCR tests for this disease were negative.

On admission, a diagnosis of non-infectious exacerbation of COPD was made, overlapping the chronic heart failure symptoms. The initial treatment (apart from her everyday treatment) included enoxaparin at a therapeutic dose, furosemide and nebulization with fenoterol and ipratropium bromide. NIV was used in bi-PAP mode with expiratory positive airway pressures (EPAP) of $4 \mathrm{cmH}_{2} \mathrm{O}$ and inspiratory positive airway pressures (IPAP) of $12 \mathrm{cmH}_{2} \mathrm{O}$.

Despite numerous health burdens and advanced lung disease, the patient was in a reasonably good condition, moved independently within the bed, was adapted to dyspnoea and tolerated NIV treatment well.

Due to significantly elevated levels of D-dimers and her previous history of $\mathrm{PE}$, chest angio-computed tomography 
(angio-CT) was performed, which did not confirm PE, but showed features of right ventricular failure, e.g. throwing a contrast into the inferior vena cava and hepatic veins. The cardiologist consulted the patient, on echocardiography $\mathrm{III}^{\circ}$ tricuspid regurgitation, $\mathrm{I} / \mathrm{II}^{\circ}$ mitral valve insufficiency, normal left ventricular systolic function and features of pulmonary hypertension with pulmonary systolic pressure (PASP) of $135 \mathrm{mmHg}$ were found. Due to a slight increase in inflammatory parameters, empirical antibiotic therapy with levofloxacin was commenced. On the fifth day of hospitalization, the activity of hepatic transaminases increased significantly with normal bilirubin levels (Tab. 1). Hepatoprotective treatment with timonacic and phospholipids was initiated immediately. On the seventh day of hospitalization, the activity of transaminases increased even more, but a day later it began to decline.

Table 1. Results of laboratory tests

\begin{tabular}{|c|c|c|c|c|c|c|c|}
\hline \multirow{2}{*}{ Lab test (normal ranges) } & \multicolumn{7}{|c|}{ Day of hospitalization } \\
\hline & 1 & 3 & 5 & 7 & 8 & 9 & 10 \\
\hline $\operatorname{ALT}(<34 \mathrm{U} / \mathrm{L})$ & & 50 & 659 & 1397 & 1108 & 933 & 1338 \\
\hline AST $(<31 \mathrm{U} / \mathrm{L})$ & & 28 & 1120 & 1831 & 1077 & 909 & 1905 \\
\hline AST/ALT & & 0.56 & 1.7 & 1.3 & 0.97 & 0.97 & 1.4 \\
\hline Bilirubin(0.3-1.2 mg/dl) & & 0.7 & 0.8 & 0.8 & 0.8 & 1.2 & 1.9 \\
\hline GGTP (<38 U/L) & & & & & 24 & 28 & \\
\hline ALP (46-116 U/L) & & & & & 74 & 82 & \\
\hline $\operatorname{CRP}(0-5 \mathrm{mg} / \mathrm{L})$ & 7 & 2 & 25 & 29 & 32 & 33 & 24 \\
\hline BNP (0-100 pg/mL) & & & & & 608 & & 4966 \\
\hline II-6 (< $7 \mathrm{pg} / \mathrm{mL})$ & & & & & & 50.9 & \\
\hline Albumins (3.2-4.8 g/dL) & & & & 3.65 & & & \\
\hline
\end{tabular}

On the eighth day of hospitalization, the patient's general condition suddenly deteriorated. She was drowsy and confused, with dyspnoea and central cyanosis and crackles heard above the lungs. Tachypnoea and tachycardia were observed, $\mathrm{SpO} 2$ decreased to $70 \%$ despite optimalization of NIV parameters, mask fitting and increasing oxygen flow, pH was 7.25, pCO2 $83 \mathrm{mmHg}, \mathrm{pO} 250 \mathrm{mmHg}$ and $\mathrm{HCO} 3$ - $36 \mathrm{mmol} / \mathrm{l}$. The immediate administration of furosemide and dexamethasone was ineffective and her condition continued to deteriorate. She was intubated while sedated with propofol. Due to a drop in blood pressure, the fluid supply was increased, and norepinephrine infusion was started through the central line. An antigen test for COVID-19 was performed, again with a positive result. The patient was placed in an isolation room with a sanitary regime. Meropenem and dexamethasone were added to the treatment. Efforts were initiated to transfer the patient to a department that provides specialist treatment for COVID-19 patients.

The next day, sudden cardiac arrest in the pulseless electrical activity mechanism (PEA) occurred. Circulation was restored immediately after resuscitation. Supraventricular tachycardia with hypotension was observed - dobutamine and amiodarone were added to the treatment. In the morning, two days after the exacerbation, circulation stopped for the third time, resuscitation was unsuccessful. At the request of the patient's family and due to the known cause of death, an autopsy was not carried out.

\section{DISCUSSION AND LITERATURE REVIEW}

In the presented case, the patient had numerous and severe internal diseases despite her initially stable general condition. We are convinced that the development of COVID-19 symptoms contributed to the rapid deterioration of the patient's clinical condition and to the development of multiorgan failure, including acute liver injury. Liver dysfunction in the patient did not meet the criteria of acute liver failure because neither jaundice, plasma coagulation disorders nor hepatic encephalopathy were observed.

Acute liver injury, although rare, can turn into a lifethreatening situation. Therefore, it requires a multidisciplinary approach and a quick search for causes in order to apply treatment, preferably a causal one [5,6]. In developing countries, hepatotropic viruses are the dominant cause of liver injury, while in the USA and Western Europe, the main cause is drugs [7]. We excluded numerous causes of acute liver damage in the presented patient. Being aware that viral hepatitis may, in this situation, aggravate the features of liver damage $[2,8]$, tests for hepatotropic virus infections were performed, but they were all negative. Other causes of acute liver injury were also considered, but no apparent cause was confirmed.

Drug effects accounted for $50 \%$ of the causes of acute liver damage in the United States, although the response to many drugs other than acetaminophen is unpredictable and may not be dose-related (idiosyncrasy) [9]. Risk factors include old age and baseline hypertransaminasemia [10]. Commonly used drugs that can cause the idiosyncratic acute liver failure mentioned in numerous studies are statins and amoxicillin-clavulanate $[11,12,13]$. In the presented patient, drug-induced injury seemed unlikely because she did not take medications that typically damage the liver: paracetamol, statins, or antibiotics, with the exception of levofloxacin. Liver damage after the use of levofloxacin is very rare - the percentage of patients showing elevation in alanine transaminase (ALT) and aspartate transaminase (AST) activity due to levofloxacin administration accounted for $2 \%-5 \%$. The latency to onset usually lasts $1-3$ weeks [14]. In the presented patient, starting levofloxacin and the onset of symptoms occurred on the same day, which renders any relationship between them very doubtful. In a Canadian study, the administration of levofloxacin and moxifloxacin was associated with a two-fold risk of hospital admission for acute liver injury. However, this risk was only examined in relation to the use of clarithromycin [15]. The mechanism of damage associated with fluoroquinolone intake can be hepatocellular, cholestatic, or a combination of the two [16]. It is worth mentioning that some of the drugs used in treatment of COVID-19 have been found to be toxic to the liver. These include, apart from the already mentioned antipyretic drugs and antibiotics (e.g. azitromycin), antiviral drugs like remdesivir and lopinavir/ ritonavir, immunomodulators (tocilizumab, glucocosteroids) and antimalarics (hydroxychloroquine) [17, 18, 19, 20].

In a study by Goldman et al., the use of remdesivir resulted in an increase in transaminase activity in $6 \%$ of patients [21]. Hydroxychloroquine treatment is considered as a rare cause for the elevation of liver enzymes [22]. Azytromycin can cause liver injury in hepatocellular [23] or cholestatic mechanism [24]. The use of tocilizumab can result in the elevation of liver enzymes [24] and suppression of liver regeneration [25]. It is worth noting that pre-existing, non-alcoholic fatty liver 
disease (NAFLD) can be responsible for higher susceptibility to liver damage caused by acetaminophen, compared to the healthy population [18]. In addition, patients with COVID-19 who require treatment and hospitalization are treated with numerous drugs, the hepatotoxic effects of which may overlap and intensify [20].

Another cause of drug-induced liver damage is the use of herbal drugs [26], but the presented patient did not take any herbal medications of uncertain composition, such as consumption of poisonous forest mushrooms [27]; therefore, the effect of alpha-amanitin was not confirmed. The patient had also not been exposed to carbon tetrachloride, one of the substances responsible for direct liver injury [28]. Alcoholic liver disease was excluded because the patient was completely abstinent. Other causes, such as hepatic insufficiency, Wilson's disease, auto-immune hepatitis, Rey's syndrome, sepsis, Budd-Chiari syndrome, or HELLP syndrome, also seemed very unlikely.

One of the causes of acute liver injury in the presented patient could be the exacerbation of right ventricular heart failure. The occurrence of liver injury caused by cardiac disorders in the absence of other known causes is called cardiac hepatopathy, which is usually the effect of passive venous congestion [29]. Acute cardiogenic liver injury (ACLI), also called 'ischemic/hypoxic hepatitis', is most commonly associated with acute cardiocirculatory failure resulting from acute cardiac conditions. There are different possible mechanisms responsible for hypoxic hepatitis, e.g. cellular damage caused by hypoxia induced by hypoperfusion, or hepatic congestion due to heart failure [30, 31]. However, it should be borne in mind that this cause-and-effect relationship is not very obvious or commonplace. A large study confirmed the relationship between acute liver failure and ischemic hepatitis in only $4.4 \%$ of cases [32]. It is worth noting, however, that in isolated liver injury, the activity of alanine transaminase would probably increase more than that of aspartate transaminase, which is more typical for liver cells. AST is also produced by cardiomyocytes and skeletal muscles.

All this led to the suspicion that such acute deterioration in liver function was related to the developing COVID-19. On the day of admission to the Clinic, the patient had several tests for COVID-19, which turned out to be negative. Only the test taken on the day of rapid clinical deterioration was positive.

Although respiratory symptoms are the most common in the course of COVID-19 infection, the complicated course of this disease may also lead to impairment of the functions of other organs. Among gastrointestinal symptoms, nausea, vomiting and diarrhoea were the most common during COVID-19 infection [33]; however, many reports also discuss the impact of SARS-CoV2 on many different types of liver dysfunction [34, 35, 36, 37, 38, 39, 40, 41, 42, 43, 44, 45, 46].

The abnormality found most often among liver function tests was hypoalbuminemia, followed by the increasing activity of aminotransferases [47]. Fan et al. reported that nearly $40 \%$ of patients admitted to hospital due to COVID-19 had abnormal liver function laboratory test results, with the following the percentages: lactate dehydrogenase (LDH) - 35.1\%, AST - 21.6\%, ALT - 18.2\%, gamma glutamyl transpeptidase (GGTP) - 17.6\%, total bilirubin (TB) $6.1 \%$, and alkaline phosphatase (ALP) - 4.1\% [48]. Together with the albumin level, the results of the above-mentioned laboratory tests can be used as the biochemical indicators of liver injury in the course of COVID-19, and on the other hand, abnormalities in liver function tests can be used as predictors of the severity of COVID-19 [4].

The SARS-CoV2 virus enters liver cells through angiotensin-converting enzyme-2 receptors (ACE2) [49, 50, $51,52]$ located in many tissues and liver cells-hepatocytes and cholangiocytes [52]. Chai et al. proved that the expression of ACE2 receptors, compared to hepatocytes, is much higher in cholangiocytes, which play an important role not only in bile production, but also in the immune response and liver regeneration [53]. Liver damage in the course of COVID-19 is classified into 3 main sub-types: hepatocellular, cholestatic and mixed [54]. Potential mechanisms of action of SARSCoV-2 leading to liver damage include direct cytotoxicity $[55,56,57]$, activation of the immune system in the course of viral infection, systemic inflammatory response syndrome (SIRS) and cytokine storm [55, 56], damage associated with hypoxia in the course of respiratory failure [56], congestion caused by right ventricular failure, and exacerbation of coexisting liver disease $[57,58,59]$. Biopsies of liver in patients with COVID-19 revealed the presence of micothrombi and haemophagocytes [60], which may suggest that ischemia and hypoxia developing in critically ill patients can be one of the main mechanisms leading to liver damage [34].

In laboratory tests of serum taken from the presented patient, an increased concentration of interleukin-6 (IL-6) was noted. It is now known that the increased concentration of this cytokine correlates with higher liver enzyme activity [61]. It is very likely that in this patient, acute liver damage in the course of coronavirus infection coincided with injury to this organ in the course of heart failure. We do not believe that the patient died of acute liver injury, or at least that was not the only cause of her death. It is most likely that the direct cause of death was increasing respiratory failure due to COVID-19. The example of the patient in this case report confirms previous observations that COVID-19 is a disease that can damage many organs or entire systems.

\section{REFERENCES}

1. Gracia-Ramos AE, Jaquez-Quintana JO, Contreras-Omaña R, et al. Liver dysfunction and SARS-CoV-2 infection. World J Gastroenterol. 2021; 27(26): 3951-3970. https://doi.org/10.3748/wjg.v27.i26.3951

2. Zou X, Fang M, Li S, et al. Characteristics of Liver Function in Patients With SARS-CoV-2 and Chronic HBV Coinfection. Clin Gastroenterol Hepatol. 2021; 19(3): 597-603. https://doi.org/10.1016/j.cgh.2020.06.017

3. Chaibi S, Boussier J, Hajj WE, et al. Liver function test abnormalities are associated with a poorer prognosis in Covid-19 patients: Results of a French cohort. Clin Res Hepatol Gastroenterol. 2020; 19: 101556. https://doi.org/10.1016/j.clinre.2020.10.002

4. Cichoż-Lach H, Michalak A. Liver injury in the era of COVID-19. World J Gastroenterol. 2021; 27(5): 377-390. https://doi.org/10.3748/ wjg.v27.i5.377

5. Pathikonda M, Munoz SJ. Acute liver failure. Ann Hepatol. 2010; 9(1): 7-14.

6. EASL Clinical Practical Guidelines on the management of acute (fulminant) liver failure. European Association for the Study of the Liver. J Hepatol. 2017; 66,5: 1047-1081.

7. Bernal W, Auzinger G, Dhawan A, et al. Acute liver failure. The Lancet. 2010; 376(9736): 190-201. https://doi.org/10.1016/S0140-...

8. Lin Y, Yuan J, Long Q, et al. Patients with SARS-CoV-2 and HBV co-infection are at risk of greater liver injury. Genes Dis. 2021; 8(4): 484-492. https://doi.org/10.1016/j.gendis.2020.11.005

9. Jaeschke H. Acetaminophen: Dose-Dependent Drug Hepatotoxicity and Acute Liver Failure in Patients. Dig Dis. 2015; 33(4): 464-71. https:// doi.org/10.1159/000374...

10. Bernal W, Wendon J. Acute liver failure. N Engl J Med. 2013; 369(26): 2525-34. https://doi.org/ 10.1056/NEJMra1208937 
11. Björnsson ES. Hepatotoxicity by Drugs: The Most Common Implicated Agents. Int J Mol Sci. 2016; 17(2): 224.

12. Thapar M, Russo MW, Bonkovsky HL. Statins and liver injury. Gastroenterol Hepatol (NY). 2013; 9(9): 605-606.

13. Haque T, Sasatomi E, Hayashi PH. Drug-Induced Liver Injury: Pattern Recognition and Future Directions. Gut Liver. 2016; 10(1): 27-36.

14. LiverTox: Clinical and Research Information on Drug-Induced Liver Injury [Internet]. Bethesda (MD): National Institute of Diabetes and Digestive and Kidney Diseases 2012. Levofloxacin. [Updated 2020 Mar 10]. Available from: https://www.ncbi.nlm.nih.gov/b....

15. Paterson JM, Mamdani MM, Manno M, et al. Canadian Drug Safety and Effectiveness Research Network. Fluoroquinolone therapy and idiosyncratic acute liver injury: a population-based study. CMAJ. 2012; 184(14): 1565-1570. https://doi.org/doi:10.1503/cm...

16. Orman ES, Conjeevaram HS, Vuppalanchi R, et al. Clinical and histopathologic features of fluoroquinolone-induced liver injury. Clin Gastroenterol Hepatol. 2011; 9(6): 517-523.e3.

17. Moreira JLS, Barbosa SMS, Gonçalves Júnior J. Pathophysiology and molecular mechanisms of liver injury in severe forms of COVID-19: An integrative review. Clin Res Hepatol Gastroenterol. 2021; 23; 45(6): 101752. https://doi.org/10.1016/j.clinre.2021.101752

18. Licata, A, Minissale, MG, Distefano, M, Montalto, G. Liver injury, SARS-COV-2 infection and COVID-19: What physicians should really know? GastroHep. 2021; 3: 121-130. https://doi.org/10.1002/ygh2.455

19. Vitiello A, La Porta R, D’Aiuto V, et al. The risks of liver injury in COVID-19 patients and pharmacological management to reduce or prevent the damage induced. Egypt Liv J. 2021; 11(1): 11. https://doi. org/10.1186/s43066-021-00082-y

20. Muhović D, Bojović J, Bulatović A, et al. First case of drug-induced liver injury associated with the use of tocilizumab in a patient with COVID-19. Liver Int. 2020; 40(8): 1901-1905. https://doi.org/10.1111/ liv. 14516

21. Goldman JD, Lye DCB, Hui DS, et al. Remdesivir for 5 or 10 Days in Patients with Severe Covid-19. N Engl J Med. 2020; 5; 383(19): 1827-1837. https://doi.org/ 10.1056/NEJMoa2015301

22. Sweed D, Abdelsameea E, Khalifa EA et al. SARS-CoV-2-associated gastrointestinal and liver diseases: what is known and what is needed to explore. Egypt Liv J. 2021; 11: 64. https://doi.org/10.1186/s43066021-00123-6

23. Martinez MA, Vuppalanchi R, Fontana RJ, et al. Clinical and histologic features of azithromycin-induced liver injury. Clin Gastroenterol Hepatol. 2015; 13(2): 369-376.e3. https://doi.org/10.1016/j.cgh.2014.07.054

24. Hanafy AS, Abd-Elsalam S. Challenges in COVID-19 drug treatment in patients with advanced liver diseases: A hepatology perspective. World J Gastroenterol. 2020; 14; 26(46): 7272-7286. https://doi.org/10.3748/ wjg.v26.i46.7272

25. Hiura M, Abe S, Tabaru A, et al. Case of severe liver damage after the induction of tocilizumab therapy for rheumatoid vasculitis. Hepatol Res. 2011; 41(5): 492-6. https://doi.org/10.1111/j.1872-034X.2011.00793.x. Epub 2011 Mar 21. PMID: 21435128.

26. Björnsson ES. Drug-induced liver injury: an overview over the most critical compounds. Arch Toxicol. 2015; 89(3): 327-34.

27. Kim T, Lee D, Lee JH, et al. Predictors of poor outcomes in patients with wild mushroom-induced acute liver injury. World J Gastroenterol. 2017; 21,23(7): 1262-1267.

28. Teschke R. Liver Injury by Carbon Tetrachloride Intoxication in 16 Patients Treated with Forced Ventilation to Accelerate Toxin Removal via the Lungs: A Clinical Report. Toxics. 2018; 6(2): 25.

29. Çağlı K, Başar FN, Tok D, et al. How to interpret liver function tests in heart failure patients? Turk J Gastroenterol. 2015; 26(3): 197-203.

30. Nikolaou M, Mebazaa A. Cardiohepatic interactions in heart failure: clinical and therapeutical implications, Cont Cardiol Educ. 2017; 3(3).

31. Xanthopoulos A, Starling RC, Kitai T, et al. Heart Failure and Liver Disease: Cardiohepatic Interactions, JACC: Heart Failure. 2019; 7(2): 87-97.

32. Taylor RM, Tujios S, Jinjuvadia K, et al. Short and long-term outcomes in patients with acute liver failure due to ischemic hepatitis. Dig Dis Sci. 2012; 57(3): 777-85.

33. Lee IC, Huo TI, Huang YH. Gastrointestinal and liver manifestations in patients with COVID-19. J Chin Med Assoc. 2020; 83(6): 521-523. https://doi.org/10.1097/JCMA.0...]

34. Tian D, Ye Q. Hepatic complications of COVID-19 and its treatment. J Med Virol. 2020; 92(10): 1818-1824. https://10.1002/jmv.26036

35. Mokhtari T, Hassani F, Ghaffari N, et al. COVID-19 and multiorgan failure: A narrative review on potential mechanisms. J Mol Histol. 2020; 51(6): 613-628. https://10.1007/s10735-020-099...]
36. Gurala D, Al Moussawi H, Philipose J, et al. Acute Liver Failure in a COVID-19 Patient Without any Preexisting Liver Disease. Cureus. 2020; 26,12(8): e10045. https://10.7759/cureus.10045

37. Samidoust P, Samidoust A, Samadani AA, et al. Risk of hepatic failure in COVID-19 patients. A systematic review and meta-analysis. Infez Med. 2020; 1; 28(suppl 1): 96-103.

38. Hundt MA, Deng Y, Ciarleglio MM, et al. Abnormal Liver Tests in COVID-19: A Retrospective Observational Cohort Study of 1,827 Patients in a Major U.S. Hospital Network. Hepatology. 2020; 72(4): 1169-1176. https://doi:10.1002/hep.31487

39. Makarem J, Naghibi N, Beigmohammadi MT, et al. A Case Report of Progressive Liver Failure Inappropriate to Decompensated Heart Failure Following Infection With COVID-19. Cureus. 2020; 30; 12(8): e10142. https://10.7759/cureus.10142

40. Ji D, Zhang D, Yang T, et al. Effect of COVID-19 on patients with compensated chronic liver diseases. Hepatol Int. 2020; 14(5): 701-710.

41. Khan MU, Mushtaq K, Alkaabi SR. Acute on Chronic Liver Failure Possibly the main culprit of increased mortality in COVID-19 patients with liver disease. Gastroenterology. 2020; S0016-5085(20)34945-3

42. Sarin SK, Choudhury A, Lau GK, et al. APASL COVID Task Force, APASL COVID Liver Injury Spectrum Study (APCOLIS Study-NCT 04345640). Pre-existing liver disease is associated with poor outcome in patients with SARS CoV2 infection; The APCOLIS Study (APASL COVID-19 Liver Injury Spectrum Study). Hepatol Int. 2020; 14(5): 690-700.

43. Cameli M, Pastore MC, Soliman Aboumarie H, et al. Usefulness of echocardiography to detect cardiac involvement in COVID-19 patients. Echocardiography. 2020; 37(8): 1278-1286.

44. Schattenberg JM, Labenz C, Wörns MA, et al. Patterns of liver injury in COVID-19 - a German case series. United European Gastroenterol J. 2020; 8(7): 814-819.

45. Hamid S, Alvares da Silva MR, Burak KW, et al. WGO Guidance for the Care of Patients With COVID-19 and Liver Disease. J Clin Gastroenterol. 2021; 55(1): 1-11.

46. Melquist S, Estepp K, Aleksandrovich Y, et al. COVID-19 presenting as fulminant hepatic failure: A case report. Medicine (Baltimore). 2020; 99(43): e22818.

47. Kumar-M P, Mishra S, Jha DK. Coronavirus disease (COVID-19) and the liver: a comprehensive systematic review and meta-analysis. Hepatol Int. $2020 ; 14(5)$ : 711-722.

48. Fan Z, Chen L, Li J, et al. Clinical Features of COVID-19-Related Liver Functional Abnormality. Clin Gastroenterol Hepatol. 2020; 18(7): 1561-1566.

49. Zhou P, Yang XL, Wang XG, et al. A pneumonia outbreak associated with a new coronavirus of probable bat origin. Nature. 2020; 588(7836): E6.

50. Pirisi M, Rigamonti C, D'Alfonso S, et al. Liver infection and COVID-19: the electron microscopy proof and revision of the literaturę. Eur Rev Med Pharmacol Sci. 2021; 25,4: 2146-2151.

51. Hoffmann M, Kleine-Weber H, Schroeder S, et al. SARS-CoV-2 Cell Entry Depends on ACE2 and TMPRSS2 and Is Blocked by a Clinically Proven Protease Inhibitor. Cell. 2020; 181(2): 271-280.e8.

52. Alqahtani SA, Schattenberg JM. Liver injury in COVID-19: The current evidence. United European Gastroenterol J. 2020; 8(5): 509-519.

53. Chai X, Hu L, Zhang Y, et al. Specific ACE2 expression in cholangiocytes may cause liver damage after 2019-nCoV infection. Bio-Rxiv 2020.

54. Chu H, Bai T, Chen L, et al. Multicenter Analysis of Liver Injury Patterns and Mortality in COVID-19. Front Med (Lausanne). 2020; 7: 584342.

55. Kukla M, Skonieczna-Żydecka K, Kotfis K, et al. COVID-19, MERS and SARS with Concomitant Liver Injury-Systematic Review of the Existing Literature. J Clin Med. 2020; 9(5): 1420.

56. Tian D, Ye Q. Hepatic complications of COVID-19 and its treatment. J Med Virol. 2020; 92(10): 1818-1824.

57. Nardo AD, Schneeweiss-Gleixner M, Bakail M, et al. Pathophysiological mechanisms of liver injury in COVID-19. Liver Int. 2021; 41(1): 20-32.

58. Ferron PJ, Gicquel T, Mégarbane B, et al. Treatments in Covid-19 patients with pre-existing metabolic dysfunction-associated fatty liver disease: A potential threat for drug-induced liver injury? Biochimie. 2020; 179: 266-274.

59. Anirvan P, Bharali P, Gogoi M, et al. Liver injury in COVID-19: The hepatic aspect of the respiratory syndrome - what we know so far. World J Hepatol. 2020; 12(12): 1182-1197.

60. Wang Y, Liu S, Liu H, et al. SARS-CoV-2 infection of the liver directly contributes to hepatic impairment in patients with COVID-19. J Hepatol. 2020; 73: 807-816.

61. Da BL, Kushner T, El Halabi M, et al. Liver Injury in Hospitalized Patients with COVID-19 Correlates with Hyper Inflammatory Response and Elevated IL-6. Hepatol Commun. 2020; 16; 5(2): W177-88. 